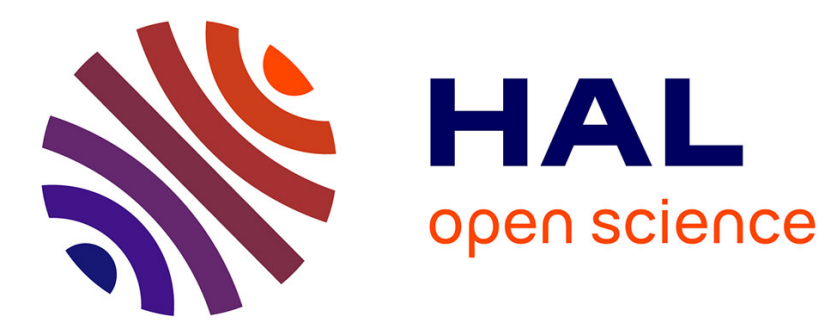

\title{
Beyond Productivity Strategies in Services
}

Faridah Djellal, Faïz Gallouj

\section{To cite this version:}

Faridah Djellal, Faïz Gallouj. Beyond Productivity Strategies in Services. Journal of innovation economics, 2010, 5 (1), pp.89-104. halshs-01133789

\section{HAL Id: halshs-01133789 \\ https://shs.hal.science/halshs-01133789}

Submitted on 20 Mar 2015

HAL is a multi-disciplinary open access archive for the deposit and dissemination of scientific research documents, whether they are published or not. The documents may come from teaching and research institutions in France or abroad, or from public or private research centers.
L'archive ouverte pluridisciplinaire HAL, est destinée au dépôt et à la diffusion de documents scientifiques de niveau recherche, publiés ou non, émanant des établissements d'enseignement et de recherche français ou étrangers, des laboratoires publics ou privés. 


\title{
Beyond Productivity Strategies in Services ${ }^{1}$
}

\author{
Faridah Djellal and Faïz Gallouj \\ University Lille 1, Clersé
}

\begin{abstract}
(Published in Journal of Innovation Economics: DJELLAL F., GALLOUJ F. (2010), Beyond Productivity Strategies in Services, Journal of Innovation Economics, $n^{\circ}$, 2010/1, p. 89-104.)
\end{abstract}

\begin{abstract}
:
Productivity in its relationships with services raises two issues: a definition and measurement issue, on the one hand, and an issue related to the productivity strategies implemented, on the other hand. This article addresses both issues, focusing more on the latter. Our goal is to account for the various productivity strategies implemented within services firms and to analyse their implications in terms of productivity definition and measurement. This analysis will allow us to discuss the role of the productivity concept and the relevance of the "productivity regime concept » in a post-fordist economy of services, quality and innovation.
\end{abstract}

Key words: services, productivity, performance, strategy

\section{Introduction}

The concept of productivity saw the light of day in industrial and agricultural economies. It can be said to have reached the apogee of its reign in economies dominated by a Fordist growth regime, that is a regime based on productivity gains obtained through increasing mechanisation, a deepening division of labour and the exploitation of economies of scale, mass consumption of standardised products and wages indexed to productivity. To a certain extent, therefore, it is the Fordist concept par excellence. The debates it sparks off in such a context are concerned with (incremental) improvements to a notion that is universally accepted (even by the social actors, although they may be at loggerheads with each other over the distribution of productivity gains).

The advent of the service economy (considered from both the functional perspective, that in terms of service functions within manufacturing industry, and from the sectoral point of view) has called into question in a much more fundamental way the methods used to measure productivity, with some commentators even going so far as to question the very validity of a concept adjudged to be outdated and obsolete (Gadrey 2001; Delaunay 2002). Service specificities have consequences on the definition and measurement of productivity. They also have consequences on the nature of the productivity levers and on the strategies implemented to improve productivity, in other words on what Regulation theory calls «productivity regime » (Petit 1998).

Service specificities modify the structure of the «productivity regime » (ie the nature and the combination of factors that are source of productivity gains). Neverthess, as far as they

1 This paper draws on a research carried out within the servPPIN project (European Commission, FP7) 
question the productivity notion, it can be asked whether they do not also question the validity of the notion of «productivity regime » itself. It is to this question of the consequences of specificities of services on the «productivity » and «productivity regime » notions that this paper is devoted. This paper aims at accounting for the main strategies implemented within service firms and sectors as regards productivity challenges and also to assess the ability of the productivity regime notion to grasp these challenges.

The productivity strategies adopted in services can be based on three different principles. The first involves doing everything possible to ensure that services resemble (standardised) goods. This is the assimilation principle. The second involves taking advantage of the specificities of services (particularist or differentiation principle). The third and final one (synthesis or integration principle) constitutes an attempt to strike a balance between the previous two principles; this can be done in various ways, for example by adopting assimilation strategies in certain areas of the activity and differentiation strategies in others, or by developing integrated systems. These three groups of generic strategies differ in the levers used, the way in which the different levers are incorporated into the strategy and the place occupied by productivity in the strict sense.

\section{Assimilation strategies: productivity as target}

The aim of asimilation strategies is to eliminate the specificities of services, to make them differ as little as possible from goods. Consequently, they have to be made less ill-defined, less (or not at all) interactive and less immediate. Diversity has to be reduced in order to develop a product that can be embodied in an explicit contract. When these aims are achieved, the determinants of productivity are absolutely the same as those used in manufacturing. It follows, therefore, that attempts can be made to improve productivity by drawing on any of the traditional productivity factors (technical, human, organisational...). The regulationist notion of "productivity regime" defined as a resources system oriented towards productivity gains is valid.

Thus assimilation strategies are synonymous with industrialisation strategies. Despite being frequently used, this notion is particularly vague and can mean several different things. It can be assumed, as Gadrey (1996) suggests, that in general terms, 'the notion of industrialisation denotes a process whereby an organisational category that is not part of the industrial world tends to move closer to that world, at least on certain levels that are regarded as significant'. An analysis of what characterises the industrial world in terms of its operational principles (particularly work organisation and performance assessment criteria) reveals various complementary facets of industrialisation.

a) Thus according to Gadrey (1996), if the industrial world is defined by its production of material or tangible goods, then industrialisation denotes a process of evolution towards the production of tangible goods, to the detriment of the provision of intangible services. In other words, the industrialisation of services involves replacing intangible services with tangible goods that provide (or are supposed to provide) the same utilities. The best-known theoretical model developed on this basis is probably the theory of the self-service society developed by Gershuny (1978).

b) If the industrial world is defined in terms of a certain mode of production (the type of work organisation and technologies that predominated in the heavy industry of the post-war period), then industrialisation will denote the tendency to transfer that mode of production to service 
firms and organisations. As Gadrey (1996) rightly notes, given the extreme diversity of past and present manifestations of the industrial world, any reference to that world loses its meaning if the particular industrial world in question is not specified. The most practical and most frequently used reference point is probably the heavy industry of the post-war period. In this case, the industrial world (the model for the industrialisation of services) can be described in terms of the following characteristics (Gadrey 1996):

- the work procedures in use in operational centres, which are responsible for producing or selling goods or services, are highly standardised and specialised (rigid division of labour);

- the job of the specialists in the technostructure is to design the organisations and standardise and monitor tasks ;

- the organisations produce standardised services (quasi-products) on a large scale (mass production);

- these organisations prove to be fairly effective in a simple and stable environment. They enter into crisis when this environment becomes complex and uncertain.

In the first case, industrialisation is regarded as the process leading to the replacement of services by manufactured goods used in the home (self-service), for example. the substitution of domestic washing machines for launderettes or watching a DVD at home rather than going out to the cinema, etc. In the second case, industrialisation denotes the standardisation of work procedures which, in the case of services, is synonymous with or leads to standardisation of the service itself. The product, in this case, is not a good but a quasiproduct: e.g. a standard insurance policy or financial product, a standard holiday, a standard fixed menu in a fast-food restaurant. In this case, industrialisation means ceasing to handle non-standard cases.

In the management literature, the assimilation strategy has sometimes been established as a strategic rule. Levitt (1972) advocates the systematic industrialisation of services, particularly through the use of industrial production methods. Similarly, Shostack (1984) sees this industrialisation strategy as a solution to the 'divergence' (degree of freedom) and complexity of service provision; at the same time, she recommends (Shostack 1984) the development of flowcharts or blueprints of the service delivery process (see also Lovelock 1992; KingmanBrundage 1992).

c) There is probably another mode of industrialisation, which is located at the intersection between the previous two. It is associated with information and communication technologies, and in particular with their use in service delivery. After all, the provision of a wide and open range of electronic services, in a variety of different fields, also reflects a certain form of industrialisation. However, it is true that computerisation in its decentralised, networked form can also be seen as a fundamental factor in integrationist productivity strategies, serving as a basis both for 'servicisation' processes assisted by decentralised computer systems and for more standard industrialisation processes associated with back-office computer systems.

d) Industrialisation can also be defined in terms of performance assessment criteria. Thus industrial rationalisation emphasises productivity, that is quantitative measurements based on groups of standard cases. This form of rationalisation uses productivity indicators to evaluate performance. The hypothesis advanced here is that measurement of these indicators may indeed pose problems in services but that those problems can be resolved by methodological improvements and technical refinements. Above all, however, this form of rationalisation leads to products being designed (both in their functional characteristics and the processes used to produce them) in such a way that they can be measured in terms of productivity 
indicators. In other words, assimilation strategies are not confined simply to application of a technical concept, which is valid by definition, but they also construct that validity. They influence both theoretical concepts and products.

Assimilation strategies contributed to the success of the Fordist growth regime. They didn't disappear in the Pots-Fordist regime (fast-food, low-cost, discount). But they are not dominating anymore. However the measurement issue, even in a Fordist growth regime, is far from being satisfactorily solved. Defining and measuring volumes in services is often difficult both in a Fordist and Post-Fordist growth regime. Let us examine the standard example of large scale retailing which is often considered within services as the epitome of the Fordist regime (just as car manufacturing within manufacturing). Nevertheless the 'retail service' or the 'production of retail services' is still valued in terms of the volume of goods sold. Indeed, there is currently no other means of identifying 'units' of retail service to which unit prices might be linked. Now the 'retail service' cannot be reduced to volumes of goods sold. In varying proportions depending on the type of outlet and the country in question, it consists of a certain number of characteristics that play a part in defining the 'retail service' (and which also explain consumers' preferences for one type of outlet over another). These characteristics include, for example, product quality, the range of products on offer, the quality of the service provided, geographical accessibility, etc. These characteristics have to be taken into account in any attempt to calculate a volume of retail service. Failure to do so means that productivity will be underestimated in the case of those retail outlets that provide enhanced levels of service. This is unacceptable, since different outputs are then being compared in time or in space.

\section{Differentiation strategies: effectiveness regime and conceptual invalidation of the notion of productivity}

Just like assimilation (or industrialisation), which can only be considered as regards a given industrial model, considered as the reference model of the manufacturing world, differentiation should also be envisaged in relation to a reference model (ideal-type), as far as in contemporary economies numerous manufacturing activities do not differ from services in terms of the immateriality and interactivity characteristics.

The dominant hypothesis here is that services have certain specificities that have to be taken into account or that have to be maintained (i.e. prevented from disappearing). Consequently, industrialisation in the sense of the term used in the previous section is neither practicable nor desirable. This does not mean, however, that all strategies for improving productivity or performance have to be abandoned. Indeed, there are certain strategies for rationalising production processes and products at work (or waiting to be mobilised) that should not be confused with industrialisation. Some service activities are better suited than others to these particular strategies, the main ones being services with a high cognitive and relational content (professional services).

\subsection{Differentiation and the conceptual validity of the notion of productivity}

In some situations, the concept of productivity quite simply loses its validity. No amount of technical adjustments can resolve this problem. The only solution is to stop using this concept in order to evaluate the performance of an individual, a team or an organisation. There are activities in which the concept of productivity has no meaning, since it is irrelevant to the main issues at stake, which lie elsewhere (creativity, quality of solution, etc.). This applies to 
the wind quintet concert suggested by Baumol (1967), as well as to all forms of artistic creation, etc.

There are other cases, in which the concept of productivity does not necessarily lose all its validity but no longer retains its position of supremacy. This might be described as a partial invalidation. This case reflects the difficulties that arise when the industrial concept of productivity comes up against what is known as the information or knowledge economy or society. The knowledge society is, after all, characterised by a sharp increase in the cognitive content of economic activities (knowledge being not only their input but their output as well) and by a proliferation of service relationships between providers and clients.

The problem this raises is how to measure the productivity of social relations, on the one hand, and of knowledge, on the other. Now in such an economy (which Karpik calls a "quality economy"), the quantities or volumes of output and prices matter less than their longterm useful effects, otherwise known as outcomes. A lawyer's productivity is of no significance if it ends in judgements that are unfavourable to his clients, that of a doctor is of little importance compared with the results of the treatment provided and a researcher's productivity means nothing unless it is compared with the quality of the results obtained. In all these cases, in which the outcome is subject to considerable uncertainty (where there is a high level of informational asymmetry), the mechanisms that produce trust are more important than any measurement of output or productivity.

The (partial) conceptual invalidity argument now applies to many more economic activities than the total invalidity one. After all, the knowledge society seems to be a universal phenomenon. It manifests itself not only in services but also in manufacturing industry, where there has been an increase in service activities that has been described as an 'intensification of the symbolic activities and social interactions implied by the productive process' (Perret 1995). Although this partial conceptual invalidity argument may apply to very diverse activities, it particularly affects knowledge-intensive service activities that can be defined as information and knowledge-processing machines. Organisations' internal strategic design, planning and steering functions fall into this category. Thus this partial invalidity argument can also be applied to such functions.

\subsection{Differentiation and the nature of productivity strategies}

The dominant hypothesis here is that services have certain specificities that have to be taken into account or that have to be maintained (i.e. prevented from disappearing). Consequently, industrialisation in the sense of assimilation strategies is neither practicable nor desirable. This does not mean, however, that all strategies for improving productivity or performance have to be abandoned. Indeed, there are certain strategies for rationalising production processes and products at work (or waiting to be mobilised) that should not be confused with industrialisation. Some service activities are better suited than others to these particular strategies, the main ones being services with a high cognitive and relational content (professional services).

Gadrey (1996) uses the term 'professional rationalisation' to denote these strategies for improving the performance of professional services. According to Gadrey (1996), this professional rationalisation, which should not in any way be regarded as synonymous with industrial rationalisation (or industrialisation), manifests itself in two different ways: 
1) institutional rationalisation (regulation), which involves establishing rules governing the entire profession. The most obvious of these rules are the barriers erected at the entry to certain professions. However, there are also rules that fix or influence working methods and procedures (particularly good and bad working practices).

2) cognitive rationalisation, which can be embodied in three strategies: a) the standardisation ('typification') of cases, b) the formalisation of problem-solving procedures (methods) and c) the use of individual or organisational routines. As far as the process of standardisation in consultancy services is concerned, the aim will be, for example, to identify standard cases, standard contracts and standard solutions. Efforts to formalise cognitive procedures will focus on the development of problem-solving methods or methodologies. Routines, for their part, are automatic response programmes to the problems encountered by individuals or organisations. They are acquired through individual or organisational learning processes. The standardisation ('typification') of cases, the formalisation of methods and the use of routines are not, of course, rationalisation processes that exist independently of each other. This is particularly evident in the last two cases, since methods can be defined as the linking of routines in sequence.

It is this second type of rationalisation that is of greatest significance for our investigation of performance and productivity. After all, it is at this level that a firm can really have a decisive effect on the levers of performance. This cognitive rationalisation has several effects or consequences. Firstly, it is a means of saving on resources, particularly time. Standardisation ('typification'), formalisation and routines make it possible to perform the same tasks more quickly. They are sources of productivity gains. Nevertheless, the dominant criterion for assessing performance is not productivity. In professional rationalisation, multi-criteria and multi-actor assessment indicators are favoured, with an emphasis on monitoring outcomes and adherence to the profession's quality standards. Cognitive rationalisation emphasises the accumulation of past experience and the establishment of an organisational memory. Ultimately, it enables firms to become the dominant partner in their relationships with customers by exploiting the difference in expertise derived from past experience (memory) and the competitive advantage conferred by improvements in methodology.

In earlier studies of consultancy activities (Gallouj 1994), we identified two generic modes of accumulating and circulating expertise and experience in which the various aspects of this cognitive rationalisation are reflected: 1) firstly, strategies whose aim is to accumulate knowledge within consultants' memories or to optimise the accumulation process (recruitment and outplacement strategies, training and socialisation strategies, etc.); 2) secondly, modes of accumulation based on physical media, such as paper and computer and audiovisual media. A variety of situations can be observed here, ranging from the mechanical accumulation of output to strategic accumulation based on clearly defined procedures and mechanisms and objectives consistent with the consultancy company's overall strategy.

When professional rationalisation is taken to extremes, it is impossible not to equate it with industrialisation. Thus there are professional service activities that are concerned only with identified standard cases. In the area of medical services, for example, one example would be a private clinic that treats only inguinal hernias and has taken standardisation to the point where obese people or patients with a history of heart disease suffering from hernias are refused treatment (Djellal and Gallouj 2005). This clinic provides highly standardised treatment packages and makes use of surgeons who have achieved high levels of productivity in their work. In some areas there are also clear trends towards self-service. However, as 
Gadrey (1996) notes, this industrialisation of professional services has to be regarded as the exception rather than the rule.

According to Gadrey, several arguments can be advanced to explain why most professional services are unlikely to be industrialised and, consequently, why particularist strategies are likely to be favoured, at least in many professional services.

The first argument is that standardisation, the development of 'quasi-products', cannot be reduced to a strategic decision taken by a service provider. It is not sufficient simply to decide that it will happen, since it depends crucially on the 'nature of the problems to be solved'. However, the nature of these problems, like the corresponding solution, often proves resistant to any attempt at standardisation. Since the customers themselves have a high level of professionalism, implementing standardised solutions is often perceived as intellectual weakness on the service provider's part, when it is not seen as a swindle pure and simple. The second argument is that the service relationship is fundamental to this type of activity, whether in identifying the problem or jointly developing a solution. Standardisation, however, simply serves to undermine that relationship or even destroy it altogether. The third argument concerns the information sources required for industrialisation. In the industrial model, the technostructure holds the information required to develop and monitor procedures. In professional services, however, it is the professionals themselves (consultants, doctors, professors) who hold the information required for industrial rationalisation of work procedures and not the technostructure or the management structure, where they exist.

It can be concluded that differentiation strategies are not productivity strategies strictly speaking. They do not contribute to a "productivity regime" but rather to an "effectiveness regime " mainly focused on the outcome. In such a regime, productivity doesn't necessarily disappear, but it holds a relatively weaker position.

\section{Integration strategies : multicriteria evaluation, performance regime}

Different arguments can be deployed to justify differentiation and assimilation strategies. They may be necessary, to some extent, because of the basic nature of the service in question: industrialisation may seem either unlikely (this applies to most professional services, particularly consultancy services) or, conversely 'natural'.

Both types of strategy may result from a managerial decision taken in the light of the economic and technological environment (a different choice being conceivable). Thus at any given time, service firms operating in the same sector may make different strategic choices. Thus a firm in the restaurant business might adopt an assimilation strategy (i.e. industrialisation) by developing the fast-food formula (Taylorist division of labour in a highly mechanised central kitchen, very limited customer contact), the most famous example being that of McDonald's, of course. Conversely, it might adopt a particularist (differentiation) strategy based on an artisanal (and artistic) form of work organisation and extensive customer interaction.

Integration or synthesis strategies attempt, within the same company, to strike a balance between the two previous objectives. Their implementation militates in favour a multicriteria evaluation of performance. 


\subsection{Integrating assimilation and differentiation}

However, firms can simultaneously adopt opposing differentiation and assimilation strategies. This is what we denote here by the term synthesis or integration strategies. Such strategies are particularly common in large companies in the banking, insurance, retail and distribution, tourism and transport sectors, for example.

Strategies which, at certain times (today in particular), have been described as integration strategies are in reality frequently part of an historical process that has unfolded in two successive phases, the first dominated by assimilation strategies (industrialisation) and the second by differentiation strategies, reflecting the rise to prominence of the service dimension. In other words, in the service activities under consideration here, there was initially a tendency to replace the original artisanal mode of organisation with an industrial mode based on productivity gains; this was followed by a second phase in which customised services, the service relationship etc. were reintroduced (Sundbo 1994, 2002). The term synthesising or integration strategy is used to reflect the fact the new differentiation strategies did not replace the assimilation strategies.

\subsection{Some sectoral illustrations}

This progression over time from industrialisation to a renewed emphasis on the specificities of services (servicisation), as well the possible co-existence of these two approaches in certain firms, can be illustrated by examples drawn from a number of service activities.

The (long-term) development of large cleaning companies is our first, very interesting example. The industrialisation phase, which seems particularly appropriate for a highly labour-intensive, low-skill activity, essentially involved increasing capital intensity by introducing various cleaning technologies (robotisation of certain cleaning processes, installation of specific cleaning cradles, introductions of trolleys adapted to particular environments, etc.), putting in place standard cleaning protocols and monitoring work (e.g. through the use of quality control and job description software, etc.) in order to obtain a standardised output, namely 'surface cleanliness'. The subsequent differentiation phase (servicisation) was characterised by an increase in the diversity and complexity of the 'outputs'. Thus these firms moved from providing a standard cleaning service that made intensive use of low-skill labour towards services requiring high skill levels and a certain degree of initiative: bio-cleaning in hospitals, cleaning integrated into the production and bacteriological monitoring processes in the agro-food industry, 'computer cleaning' etc.

Examination of the long-term evolution of the retail and distribution sector shows that, from the 1940s and 50s in the USA and from the 1970s in France, supermarkets followed a natural technological trajectory of increasing mechanisation and economies of scale based on two fundamental innovations: self-service and the establishment of chains of stores. For a long time, the innovation model at work focused essentially on the materials logistics function (introduction of Fordist logistical systems) and on strengthening the self-service relationship and then, in a second phase, on the information logistics function. For some years in the USA, and more recently in France, change in the retail and distribution sector has taken two new directions, both of which fall within the scope of a relational trajectory (Gadrey, 1994) :

1) the addition of 'new services' or new service relationships, which equate to new functions or sets of new service characteristics and reflect the adoption of two different strategies (which sometimes become merged): supply support strategies and strategies based on the 
conquest of new markets. The new services include, for example, information terminals for customers, bagging at the checkouts, crèches, home deliveries, the development of financial and insurance services, the opening of travel agencies and petrol stations and the introduction of individualised counter services ;

2) the improvement of service relationships through the introduction of loyalty and credit cards and other benefits for loyal customers.

In other words, the natural (material and informational) technological trajectory that is still at work has had another trajectory superimposed on to it, one that might be described as a contact or relational service trajectory.

Finally, the dialectic between industrialisation (assimilation) and servicisation (particularism or differentiation) is particularly evident in financial services. Large banks and insurance companies today combine standardised quasi-products and automated self-service, on the one hand, with 'high value-added' and tailor-made services, on the other, these latter developed in the context of highly interactive service relationships in which customers play an active role. The first alternative reflects a strategy based on industrial rationalisation, the second one a strategy based on professional rationalisation, in which standardisation is rejected in favour of the development of problem-solving methods (in the style of consultants' methodologies).

\subsection{The need for a multi-criteria evaluation}

These integration strategies militate in favour of a multicriteria evaluation of performance in which productivity looses its supremacy. Nevertheless, nobody is suggesting that the criterion of productivity (or, at the macroeconomic level, the closely associated one of growth) should be abandoned completely. The usual recommendation is to abandon the absolute power (whether on the theoretical or operational level) of a single ratio (productivity or growth) and replace it with a pluralist and flexible evaluation system (in which simply abandoning the concept of productivity would, under certain circumstances, be a possible, albeit extreme option).

Abandoning the absolutism of productivity (and of growth) is justified by a number of arguments, outlined above, that cast doubt on the validity of the concept in certain situations. Regardless of the activity in question, indeed, productivity is always inaccurately estimated (although to varying degrees depending on the activity). It suffers from chronic mismeasurement. However, there are other arguments that also cast doubt on the absolutism of productivity (and of growth) and militate in favour of a pluralist approach.

Thus, in a given economic activity, performance is not an objective category but rather is considered in different, even contradictory terms depending on the actors concerned (individuals, firms, political authorities). The subjective nature of performance, which certainly applies to tangible goods, is particularly pronounced in the case of the 'goods' produced by the information and knowledge economy, which are based on intangible, abstract and socially constructed factors of production.

Account also has to be taken of the perverse effects of certain goals or targets. For example, at both the macro and microeconomic level, the drive for growth and productivity generates negative externalities. It may give rise to certain social or environmental costs (stress and other health problems, on the one hand, environmental degradation, on the other) that are not taken into account in estimates of growth and productivity. At the microeconomic level, the frequently criticised link between overly aggressive productivity strategies and a deterioration 
in quality is well known. In the administration of justice, attempts to rationalise processes (reduction in time taken to deal with cases) are acceptable only if they can be achieved without detriment to the rights of the accused. A productivist approach could sow the seeds for wrongful convictions, for example by generating excessive pressure to obtain confessions.

More generally, the level of production of goods and services is not the only indicator of a society's well-being. Nor is it necessarily the best one. Alternative macroeconomic indicators of development are now being developed, which could be adapted for use at the level of firms and organisations (for a survey, cf. Gadrey and Jany 2007). One of the best-known of these indicators is probably Osberg and Sharp's index of economic well-being, which is made up of variables associated with the following four components of economic well-being: consumption flows, capital accumulation, inequality and poverty and economic insecurity. At the microeconomic level, dissatisfaction with the concept of productivity manifests itself in other ways. Stankiewicz (2002), for example, has suggested replacing it with a concept he denotes by the term valorité. This new concept is an attempt to do full justice to the effectiveness of labour, not simply in terms of increasing output but also as a factor in the creation of value. However, valorité is not a means of measuring productivity in value terms. Rather it denotes the effectiveness of the production of output in quantitative terms as well as other factors that may be more important than the volume of output produced, such as quality, responsiveness to demand, customer satisfaction, etc. Shifting from the concept of productivity to that of valorite also entails a change in the neoclassical view of the workforce. This new perspective (described as neo-Schumpeterian) includes a recognition that the workforce has more extensive competences that go beyond the ability to influence volumes (traditional neoclassical concept) to include the ability to influence the nature or quality of the output. This capacity for action depends not only on routines but also on capacities for adaptation and creativity that differ from one employee to the next. In order to take account of this neo-Schumpeterian concept of labour and to supplement the concept of the marginal productivity of labour, Stankiewicz proposes and formalises the concept of 'differential valorité' which takes into account differences in individual workers' abilities to make use of routines and to adapt to change.

For other activities (particularly at the intra-organisational level), comparisons of productivity are unfair, counter-productive and discouraging for the units in question. This is because they carry out their activities in environments that may differ considerably from each other, making mechanical comparisons very difficult. This applies, for example, to comparisons of post offices or schools located in very different socio-economic environments.

In certain cases, finally, the concept of productivity loses its validity or, without losing its relevance entirely, becomes insignificant compared with other aspects of performance. Thus the productivity (technical efficiency) of health and social services is a secondary issue comparing with outcomes as essential as containing outbreaks of chikungunya fever or avian flu, to take just two topical examples.

In conclusion, in a Postfordist economy (a service, innovation, quality or knowledge economy), the strategies implemented within service firms and sectors are characterised by their variety. They contribute to or are inserted in a "performance regime ", which doesn't reject the productivity regime, but which considers it just as one performance category among others. 


\section{Conclusion}

The number and diversity of studies devoted to examining productivity levers and strategies in services, particularly in management sciences, make any attempt to investigate these questions a difficult exercise indeed. It is this difficulty that justifies the general and theoretical approach to these questions that we have adopted in this paper.

We have sought in this paper to account for how service firms and sectors address productivity challenges, and consequently how these strategies relate to a central concept of regulation theory i.e. productivity regime. We suggest making this concept evolve to the larger concept of performance regime (integrating a variety of approaches of performance), which would be more adapted not only to the service economy, but also to the whole knowledge or quality economy.

We identified three generic productivity strategies. Assimilation strategies, firstly, involve transforming services into goods or quasi-goods. Such strategies transfer the traditional industrial processes of mechanisation, division of labour and specialisation to services. The aim is to achieve productivity gains by trying to make the services in question as tangible as possible, with the least possible degree of interaction. It is consistent with and it reinforces the Fordist growth regime. However, differentiation strategies are not synonymous with disorder and confusion. They do not ignore rationalisation or the specificities of services. Rather, they attempt to implement rationalisation techniques and methods that are adapted to services. Thus they eschew industrial rationalisation (which predominates in assimilation strategies) in favour of professional rationalisation based, according to Gadrey (1996), on the standardisation (typification) of cases, the formalisation of procedures and the use of routines. This professional rationalisation gives rise not only to productivity gains but also to improvements in quality and in indirect outputs, that is the outcomes for consumers of the services. A theoretical approach based on the "productivity regime" strictly speaking is therefore inadequate. It has negative impact on a relevant understanding of the postfordist mode of regulation. We proposed to replace it with the "effectiveness regime" notion, which analyses economic activity not only in terms of output (and volume) but also in terms of outcome. Integration strategies, finally, involve combining the previous two opposing strategies in different ways. They contribute to a "performance regime", which can be defined as the mix of varieties of arrangements aiming at a multicriteria evaluation of product, value and performance.

\section{Bibliography}

Baumol, W. (1967). Macroeconomics of unbalanced growth: the anatomy of urban crisis, The American Economic Review, 3 (June), 415-426.

Delaunay, J.-C. (2002). La «société de service »: quelle régulation macroéconomique ? Economies et Sociétés, EGS, 4, 1119-1142.

Djellal, F., Gallouj, C., Gallouj, F. and Gallouj, K. (2004). L'hôpital innovateur: de l'innovation médicale à l'innovation de service, Paris : Editions Masson.

Djellal F., Gallouj F. (2008), Measuring and improving productivity in services, Edward Elgar Publishers.

Gadrey, J. (1996). Services : la productivité en question, Paris : Desclée de Brouwer. 
Gadrey, J. (2001). Régime de croissance, régime de productivité: peut-on penser les régulations post-fordistes avec des concepts fordistes ?, La Lettre de la Régulation, 39, December.

Gadrey, J. and Jany-Catrice, F. (2007). Les nouveaux indicateurs de croissance, Paris:

Repère, La Découverte.

Gallouj, F. (1994). Economie de l'innovation dans les services, Paris: L'harmattan.

Gallouj, F. (1999). Les trajectoires de l'innovation dans les services: vers un enrichissement des taxonomies évolutionnistes, Economies et Sociétés , EGS series, 1(5), 143-169.

Gershuny, J. (1978). After Industrial Society? The Emerging Self-Service Economy, London:Mac Millan.

Karpik, L. (1989). L'économie de la qualité, Revue française de sociologie, XXX(2), 187 210.

Kingman-Brundage, J. (1992). The ABCs of Service System Blueprinting In Managing Services, Christopher Lovelock ed. Englewood Cliffs, New Jersey: Prentice-Hall, 96-102.

Levitt, T. (1972), Production line approach to service, Harvard Business Review, 50, (September-October), 41-52.

Lovelock, Christopher (1992), “A Basic Toolkit for Service Managers”, In Managing Services, Christopher Lovelock ed., Englewood Cliffs, New Jersey: Prentice-Hall, 17-30.

Perret, B. (1995). L'industrialisation des services, in Le travail au XXI siècle: mutations de l'économie et de la société à l'ère des autoroutes de l'information, Blanc Gérard ed., Paris:Dunod, 37-38.

Petit, P. (1998). Formes structurelles et régimes de croissance de l'après-fordisme, Les cahiers du CEPREMAP, $\mathrm{n}^{\circ} 9818$.

Shostack, G. L. (1984). Service Design in the Operating Environment. In Developing new services, William George and Claudia Marshall eds. New York: American Marketing Association, Proceedings Series, 27-43.

Stankiewicz, F. (2002). Productivité ou «valorité » du salarié ? Contribution au débat sur le travail. Travail et Emploi, 91(July), 19-29.

Sundbo, J. (1994). Modulization of service production and a thesis of convergence between service and manufacturing organizations, Scandinavian Journal of Management, 10 (3), 245-66.

Sundbo, J. (2002). The Service Economy: Standardisation or Customisation?, The Service Industries Journal, 22(4), 93-116 